Research Article

\title{
The Effect of $\alpha$-Al(MnCr)Si Dispersoids on Activation Energy and Workability of Al-Mg-Si-Cu Alloys during Hot Deformation
}

\author{
Xiaoguo Wang, ${ }^{1,2}$ Jian Qin $\left(D,{ }^{2}\right.$ Hiromi Nagaumi, ${ }^{2}$ Ruirui Wu, ${ }^{1}$ and Qiushu Li ${ }^{1}{ }^{1}$ \\ ${ }^{1}$ School of Materials Science and Engineering, Taiyuan University of Science and Technology, Taiyuan 030024, China \\ ${ }^{2}$ High Performance Metal Structural Materials Research Institute, Soochow University, Suzhou 215006, China \\ Correspondence should be addressed to Jian Qin; jian.qin@uqac.ca and Qiushu Li; liqiushu@sina.com
}

Received 27 December 2019; Revised 22 February 2020; Accepted 3 March 2020; Published 20 May 2020

Academic Editor: Pietro Russo

Copyright ( 92020 Xiaoguo Wang et al. This is an open access article distributed under the Creative Commons Attribution License, which permits unrestricted use, distribution, and reproduction in any medium, provided the original work is properly cited.

\begin{abstract}
The hot deformation behaviors of homogenized direct-chill (DC) casting 6061 aluminum alloys and Mn/Cr-containing aluminum alloys denoted as WQ1 were studied systematically by uniaxial compression tests at various deformation temperatures and strain rates. Hot deformation behavior of WQ1 alloy was remarkably changed compared to that of 6061 alloy with the presence of $\alpha-\mathrm{Al}(\mathrm{MnCr}) \mathrm{Si}$ dispersoids. The hyperbolic-sine constitutive equation was employed to determine the materials constants and activation energies of both studied alloys. The evolution of the activation energies of two alloys was investigated on a revised Sellars' constitutive equation. The processing maps and activation energy maps of both alloys were also constructed to reveal deformation stable domains and optimize deformation parameters, respectively. Under the influence of $\alpha$ dispersoids, WQ1 alloy presented a higher activation energy, around $40 \mathrm{~kJ} / \mathrm{mol}$ greater than 6061 alloy's at the same deformation conditions. Dynamic recrystallization (DRX) is main dynamic softening mechanism in safe processing domain of 6061 alloy, while dynamic recovery (DRV) was main dynamic softening mechanism in WQ1 alloy due to pinning effect of $\alpha$-Al(MnCr)Si dispersoids. $\alpha$ dispersoids can not only resist DRX but also increase power required for deformation of WQ1 alloy. The microstructure analysis revealed that the flow instability was attributed to the void formation and intermetallic cracking during hot deformation of both alloys.
\end{abstract}

\section{Introduction}

Al-Mg-Si-Cu alloys (6xxx series alloys) have been widely applied in auto industry for their high specific strength, excellent formability, and corrosion resistance [1,2]. Adding of transition elements, such as Mn and/or Cr, will significantly enhance mechanical properties of $6 \mathrm{xxx}$ alloys at both ambient and elevated temperatures due to formation of $\alpha$ - $\mathrm{Al}(\mathrm{FeMnCr}) \mathrm{Si}$ dispersoids via homogenization heat treatments [3-5]. The $\alpha-\mathrm{Al}(\mathrm{FeMnCr}) \mathrm{Si}$ dispersoids can also effectively pin migration of dislocation and substructures and therefore restrain recovery and recrystallization. In these hot processings, the workability of alloys directly relates to their deformation conditions (i.e., temperature and strain as well as strain rate) [6] and their chemical composition [7] and microstructure evolution. The processing maps based on dynamic material modeling (DMM) have been proved to be an effective approach to distinguish optimum processing domains with high power dissipation efficiency from instability domains associated with microstructural defects for hot deformed alloys [8, 9]. Wang et al. [10] predicted the optimum processing parameters for 7050 $\mathrm{Al}$ alloy as $653-693 \mathrm{~K}$ and $0.001-0.18 \mathrm{~s}^{-1}$ for temperatures and strain rates, respectively. Kai et al. [11] proposed that the optimum processing window for $6 \mathrm{X} 82$ was $465-535^{\circ} \mathrm{C}$ and $0.09-1.2 \mathrm{~s}^{-1}$. Owing to alloying elements addition and dispersion strengthening, the plastic characteristics of $6 \mathrm{xxx}$ alloys with $\alpha-\mathrm{Al}(\mathrm{FeMnCr}) \mathrm{Si}$ dispersoids are quite different from those of traditional 6xxx alloys and the related study is rare. Given current status, it is necessary to clearly understand effect of $\alpha-\mathrm{Al}(\mathrm{MnCr}) \mathrm{Si}$ dispersoids on hot deformation behaviors and workability of $6 \mathrm{xxx}$ alloys.

Arrhenius type constitutive equations established by Jonas et al. [12] are also widely used to characterize flow behaviors and interpret activation energy $(Q)$ of alloys deformed over a wide range of deformation temperatures and 
stain rates. $Q$ can be expressed as necessary free energy for dislocation to slip on slip planes and hence indicate deformation resistance of alloys [13]. $Q$ was used to be treated as a constant under different hot deformation conditions, which is contrary to recent researches. The results [13] revealed that the activation energy value of AA7150 Al alloy during hot deformation was not constant but decreased with increasing of deformation temperature and strain rate. Wang et al. [10] proved that $Q$ of $7050 \mathrm{Al}$ alloy during hot deformation were greatly affected by activation of dynamic recovery mechanism. Qin et al. [14] demonstrated that the activation energy map of the composites containing Sc and $\mathrm{Zr}$ was divided into two regions associated with dynamic precipitation. Qian et al. [3] showed that activation energy increased with increasing $\mathrm{Mn}$ contents in $6082 \mathrm{Al}$ alloy. However, the influences of $\alpha-\mathrm{Al}(\mathrm{MnCr}) \mathrm{Si}$ dispersoids on activation energy evolution of corresponding alloys during hot deformation process remain rarely reported.

The hot deformation behaviors of alloys are directly affected by the dynamic balance between work hardening and softening mechanisms [15-17]. Therefore, the microstructural evolution and flow characteristics are the key to understand plastic behaviors of $\mathrm{Al}$ alloys during deformation process. It is commonly accepted that DRV and DRX are the main softening mechanisms for alloys deformed at high temperature. But how $\alpha-\mathrm{Al}(\mathrm{MnCr}) \mathrm{Si}$ dispersoids affect microstructural evolution and softening mechanics of hot deformed 6xxx is still not well clarified.

In the present study, a new type of $6 \mathrm{xxx}$ alloy with addition of $\mathrm{Mn}$ and $\mathrm{Cr}$ (donated as WQ1) was designed aiming to form fine $\alpha-\mathrm{Al}(\mathrm{MnCr}) \mathrm{Si}$ dispersoids. The hot deformation behaviors of 6061 and WQ1 Al alloys were compared as a function of deformation temperatures and strain rates. The materials constants and activation energies of the two studied alloys were derived by application of hyperbolic-sine constitutive equation. The activation energies of the two alloys as a function of deformation conditions were constructed and compared to illustrate the impacts of deformation parameters and $\alpha-\mathrm{Al}(\mathrm{MnCr}) \mathrm{Si}$ dispersoids in detail. The processing maps that present processing safe domains and flow instability domains of both alloys were also established. Effects of $\alpha$ dispersoids on dynamic softening mechanisms and working windows of studied alloys were also analyzed. The workability of both alloys was discussed in combination with processing maps and activation energy maps. Microstructure evolution of both alloys was also observed to reveal the mechanism by which dispersoids affect softening mechanisms and verify workability of the alloys during hot deformation.

\section{Experimental Procedure}

The samples used in the present work were from ingots with $150 \mathrm{~mm}$ in diameter of 6061 and $\mathrm{Mn} / \mathrm{Cr}$-containing aluminum alloys denoted as WQ1 which were fabricated by DC casting. The ingots of 6061 and WQ1 were homogenized at $555^{\circ} \mathrm{C}$ for $6 \mathrm{~h}$ with a heating rate of $111^{\circ} \mathrm{C} / \mathrm{h}$ and $530^{\circ} \mathrm{C}$ for $6 \mathrm{~h}$ with a heating rate of $133^{\circ} \mathrm{C} / \mathrm{h}$, respectively, followed by air cooling to ambient temperature. Chemical compositions of these two alloys were examined by SPECTROLAB optical emission spectroscopy and corresponding results are listed in Table 1. The cylindrical hot compression samples with $10 \mathrm{~mm}$ in diameter and $15 \mathrm{~mm}$ in height were extracted from at half radius to center position of homogenized ingots as shown in Figure 1. To characterize the distribution of $\alpha-\mathrm{Al}(\mathrm{MnCr}) \mathrm{Si}$ dispersoids in studied alloys on as-homo condition, the samples were etched in $0.5 \mathrm{wt} . \%$ HF solution for $15 \mathrm{~s}$ at ambient temperature. To determine average grain size of two alloys, the homogenized samples were anodecoated at $18 \mathrm{~V}$ in a solution of 38 wt. $\% \mathrm{H}_{2} \mathrm{SO}_{4}+43$ wt.\% $\mathrm{HNO}_{3}+19$ wt.\% deionized water for $1.5 \mathrm{~min}$.

Isothermal compression deformation tests were performed on a Gleeble-3500 thermomechanical simulator with deformation temperature ranging from 300 to $500^{\circ} \mathrm{C}$ and strain rate range of $0.01-10 \mathrm{~s}^{-1}$ to strain of 1.2. To assure a uniform deformation process, graphite foils were placed at both sides of the sample and the anvil. Thermocouples were welded on cylindrical surface of each sample to record and control deformation temperature. The samples are heated to the targeted temperature with a heating rate of $5^{\circ} \mathrm{C} / \mathrm{s}$ and soaked for $2 \mathrm{~min}$ to ensure thermal uniformity.

All deformed samples were immediately quenched into water at room temperature after hot deformation to preserve compressed microstructures. The specimens for microstructural observation were selected from the central part of the deformed samples along compression direction and metallographically prepared. Prior to electron-back scattering diffraction (EBSD) analysis, the prepared samples were electropolished in a solution (10 wt.\% perchloric acid and $90 \mathrm{wt} . \%$ ethanol) at the voltage of $20 \mathrm{~V}$ for $40 \mathrm{~s}$ to produce strain-free surface. All EBSD data was processed by commercial software HKL Channel 5. In EBSD inverse pole figures (IPF), high-angle boundaries (HABs) expressed as black lines were defined as a misorientation larger than $15^{\circ}$, while low-angle boundaries (LABs) shown as white lines are set as a misorientation between $1^{\circ}$ and $15^{\circ}$. Boundaries with misorientation less than $1^{\circ}$ were taken as noises. Microstructure evolution was studied by JEOL JEM-2100F field emission transmission electron microscope (TEM) operated at $200 \mathrm{kV}$. The TEM samples were prepared by twin-jet electropolishing method at $-20^{\circ} \mathrm{C}$ in a solution containing 75 vol.\% of methanol and 25 vol.\% $\mathrm{HNO}_{3}$. Convergent beam electron diffraction (CBED) patterns were used to measure the thickness of the observed TEM foils. The volume fraction of dispersoids of 6061 and WQ1 alloys were determined, using equation proposed by Li and Arnberg [18].

\section{Results and Discussion}

3.1. Microstructure after Homogenization Annealing. Figure 2 shows the optical microscope images of 6061 and WQ1 alloys on homogenization condition after anodecoating. The microstructures of both alloys are composed of equiaxed grains with average of $95.75 \pm 6.34 \mu \mathrm{m}$ and $216.76 \pm 13 \mu \mathrm{m}$ for 6061 and WQ1, respectively. According to previous study [19], grain size variation plays an insignificant role in affecting flow stress during high temperature 
TABLe 1: Chemical compositions of WQ1 and $6061 \mathrm{Al}$ alloys (wt.\%).

\begin{tabular}{lllllllll}
\hline Alloy & $\mathrm{Mg}$ & $\mathrm{Si}$ & $\mathrm{Cu}$ & $\mathrm{Mn}$ & $\mathrm{Cr}$ & $\mathrm{Fe}$ & $\mathrm{Ti}$ & $\mathrm{Al}$ \\
\hline WQ1 & 1.1 & 1 & 0.35 & 0.48 & 0.3 & 0.12 & 0.02 & Bal. \\
6061 & 1.08 & 1.06 & 0.34 & 0.02 & 0.17 & 0.15 & 0.03 & Bal. \\
\hline
\end{tabular}

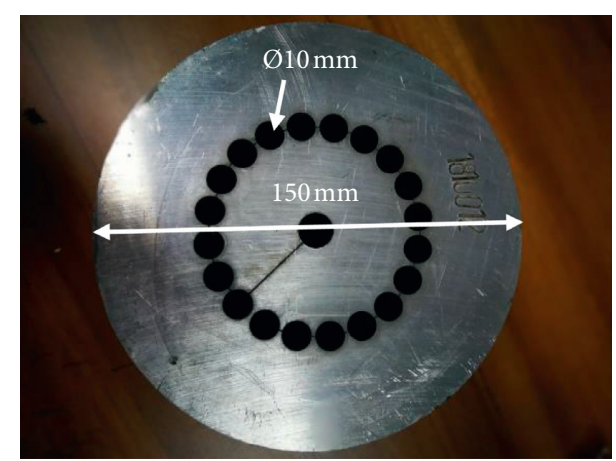

FIGURE 1: Exaction positions for deformation samples.

deformation. However, grain size in the range among commercial alloys has limit effect on flow stress.

It can be seen from dark field optical microscope images in Figure 3 that few and unevenly size of dispersoids precipitate in 6061 (Figure 3(a)) due to lack of Mn and $\mathrm{Cr}$ elements. Meanwhile fine and dense dispersoids generated in WQ1 (Figure 3(b)) during homogenization heat treatment. The distribution of dispersoids in 6061 and WQ1 alloys is inhomogeneous, especially in former, and large area of dispersoid free zone (DFZ) is observed. The nonuniform distribution of dispersoids is caused by initial segregation of $\mathrm{Mn} / \mathrm{Cr}$ at interdendritic regions during solidification [2] and low diffusion coefficients of $\mathrm{Mn} / \mathrm{Cr}$ elements.

TEM images of as-homo 6061 and WQ1 are shown in Figure 4. It is obvious that the number density of dispersoids in WQ1 is significantly higher than that of 6061. Based on quantitative analysis of TEM image of dispersoids in both alloys, the average equivalent diameters are determined as $124 \pm 6 \mathrm{~nm}$ and $129 \pm 23 \mathrm{~nm}$ for 6061 and WQ1, respectively. According to the method proposed by Li and Arnberg [18], the volume fraction of dispersoids in 6061 and WQ1 was calculated as $0.1 \%$ and $1.1 \%$, respectively. The chemical composition of the dispersoids was also examined by energy disperse spectroscopy (EDS) as shown in Figure 4(c). Based on the morphology [5] and composition, the dispersoids were identified as $\alpha-\mathrm{Al}(\mathrm{MnCr}) \mathrm{Si}$ dispersoids [20].

3.2. Flow Stress Behavior. The true strain-true stress curves of the isothermal compression deformation of studied alloys are drawn in Figure 5. It is obvious that both deformation temperature and strain rate are of great importance to the flow behaviors of the alloys. Flow stresses of both alloys increase with decreasing deformation temperatures as well as increasing strain rates. Overall, the true stress ascends rapidly at initial stage of deformation and subsequently reaches a plateau or slightly increases throughout compression process, indicating a dynamic equilibrium between work hardening and dynamic softening. All results show the flow stresses of WQ1 (Figure 5(b)) are obviously higher than those of 6061 (Figure 5(a)) under the same deformation conditions.

At initial stage, compression deformation triggers generation of massive microscopic defects (vacancies and dislocations). The complex interaction within these overwhelming microdefects causes dislocation multiplication and tangling as well as vacancy-dislocation kinking and jogging throughout the material, leading to conspicuous work hardening effect. With increasing of strain, two mutually counteracting phenomena impact the microstructure simultaneously. On one side, newly formed movable defects trapped into the preexisting dislocations and vacancies causing further strengthen work hardening. On the other side, a critical dislocation density value was reached; the dislocation cross-slip was activated along favorable slip system, resulting in dislocation annihilation and recombination as well as reduction in dislocation density. Therefore, the dynamic balance between work hardening and dynamic softening eventually developed into a steady state of flow stress during further compression. As the steady state of flow stress always presents at the strain where it reaches its peak stress, hence, peak stress is applied for the following constitutive analysis.

Figure 6 illustrates the peak flow stresses evolution of 6061 and WQ1 as function of deformation temperatures and strain rates. There is a strong connection between peak flow stresses and deformation conditions (deformation temperature and strain rates). The peak flow stresses are set as the maximum stress value of each flow curve, which increase associated with increasing strain rates and decreasing deformation temperatures. Under the same deformation condition, the peak stresses of 6061 (Figure 6(a)) are lower than those of WQ1 (Figure 6(b)), which means $\alpha$ - $\mathrm{Al}(\mathrm{MnCr}$ ) Si dispersoids considerably increase deformation resistance of WQ1. The mobility of dislocations and grain boundaries is thermally activated. Restrained by deformation temperature, lower temperature will limit DRV and DRX, therefore causing a higher flow stress. Lower strain rates can provide sufficient time for activation energy of dynamic softening mechanism leading to lower flow stress.

3.3. Constitutive Analysis. Constitutive equations are often applied to reveal the intrinsic relationships between flow stress of alloys and deformation conditions (deformation temperatures and strain rates) and predict flow stress behaviors of alloys during hot deformation. Among numerous equations, Arrhenius constitutive equation proposed by Sellars and Tegart is mostly utilized set [21]:

$$
\begin{aligned}
& Z=\dot{\varepsilon} \exp \left(\frac{Q}{R T}\right), \\
& \dot{\varepsilon}=A_{1} \sigma^{n_{1}} \exp \left(-\frac{Q}{R T}\right), \\
& \dot{\varepsilon}=A_{2} \exp (\beta \sigma) \exp \left(-\frac{Q}{R T}\right),
\end{aligned}
$$




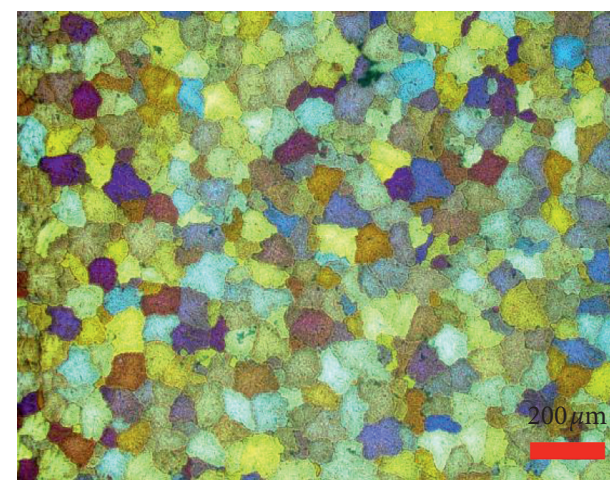

(a)

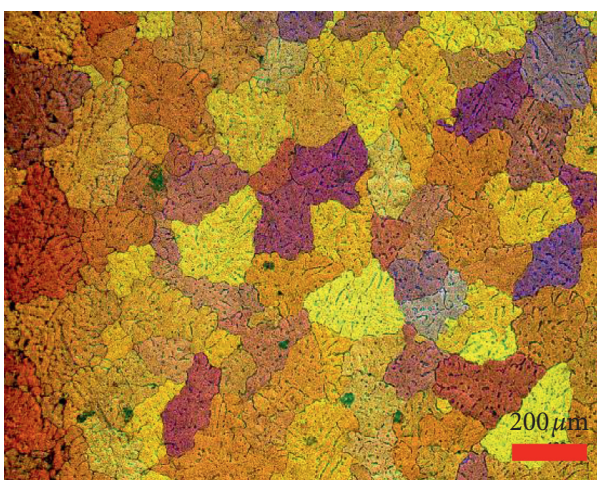

(b)

FIgURE 2: Optical microscopes images of anode-coated samples. (a) 6061 and (b) WQ1.

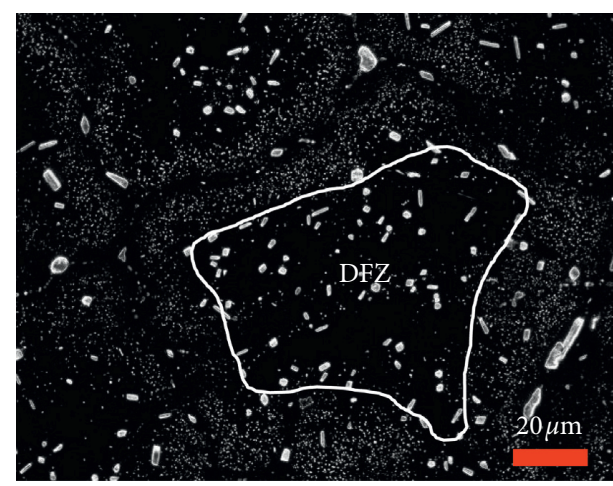

(a)

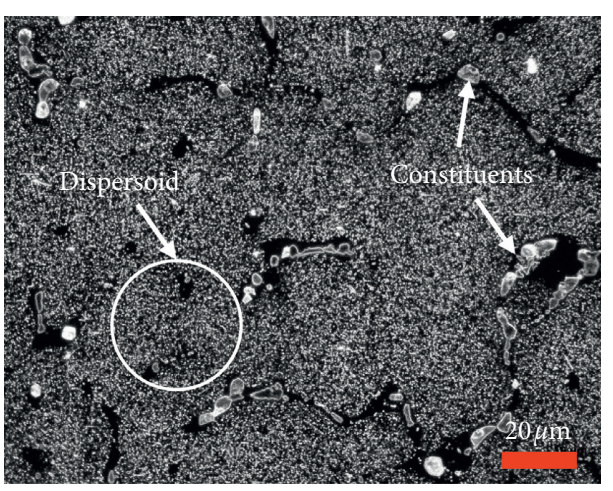

(b)

FIgURe 3: Optimal micrographs of (a) 6061 and (b) WQ1 alloys etched by HF solution.

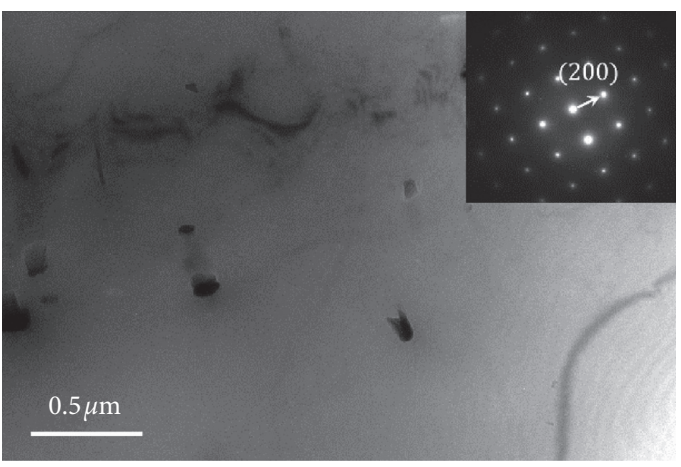

(a)

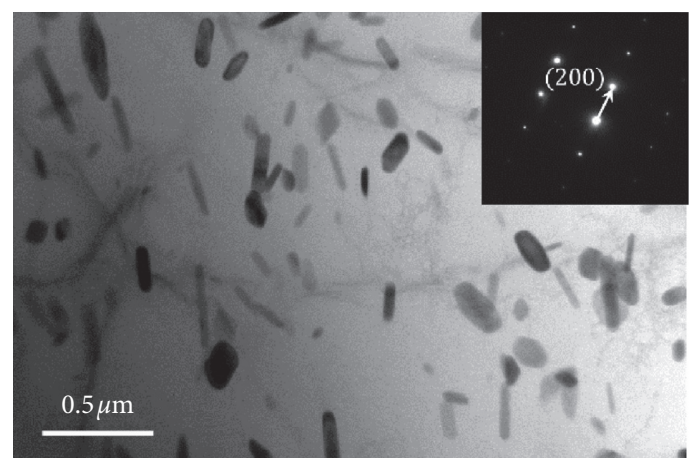

(b)

Figure 4: Continued. 


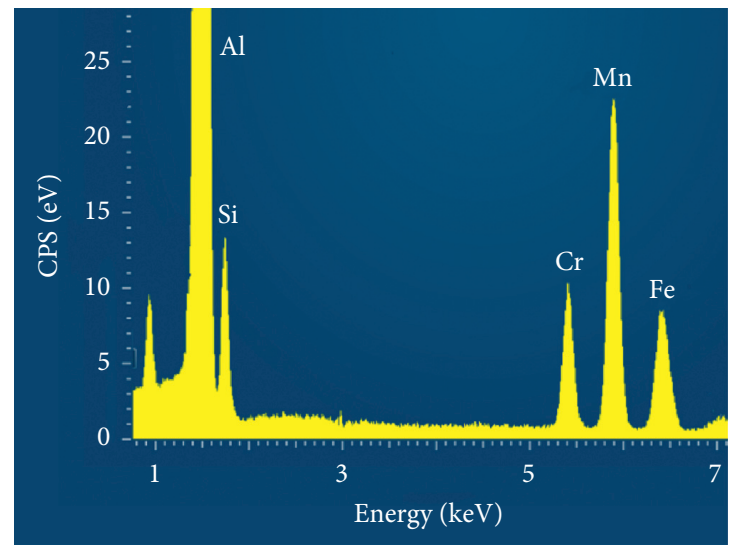

(c)

FIgURE 4: TEM images of as-homo (a) 6061 and (b) WQ1; (c) EDS of dispersoids.

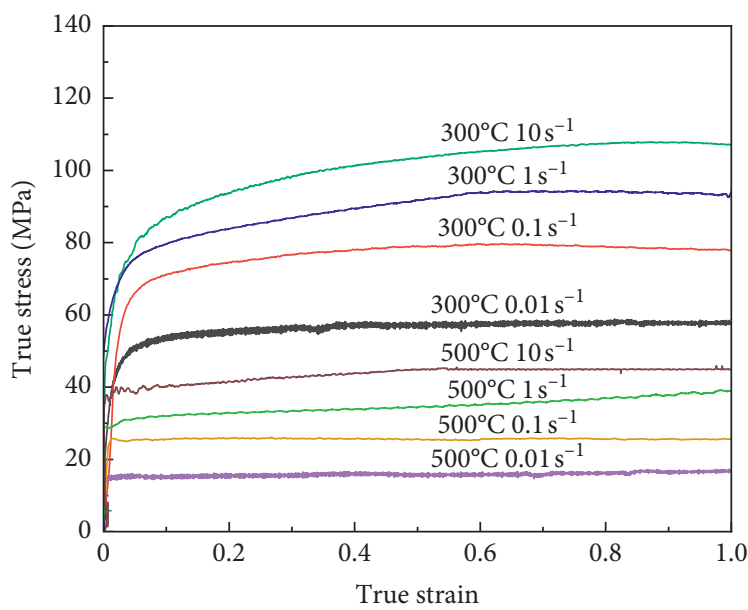

(a)

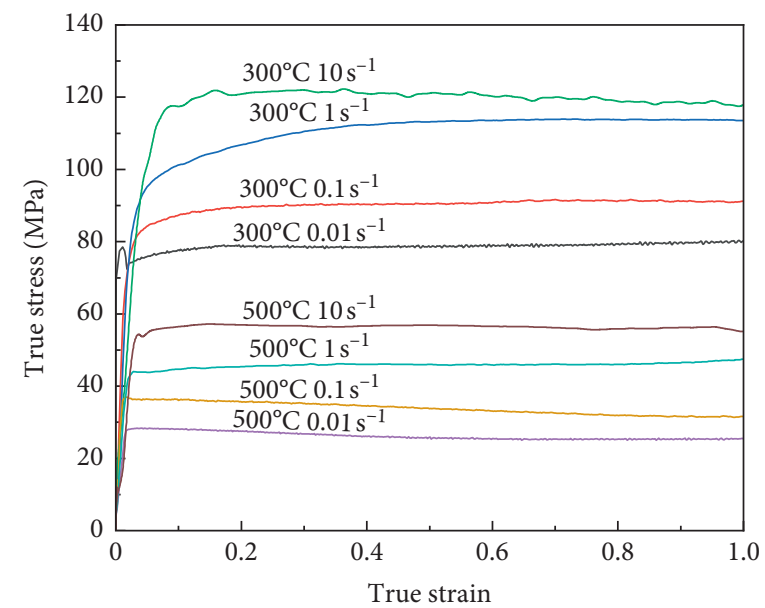

(b)

FIgURE 5: Typical true stress-true strain curves of (a) 6061 and (b) WQ1 display at two deformation temperatures and four strain rates.

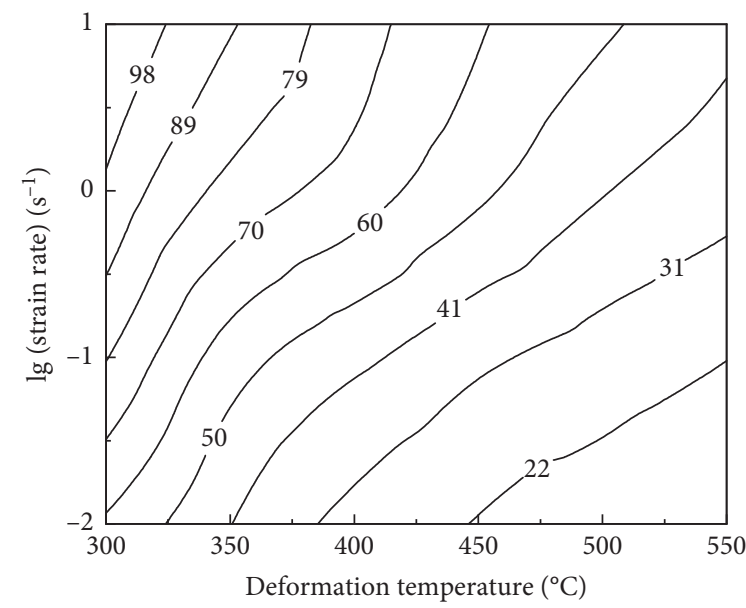

(a)

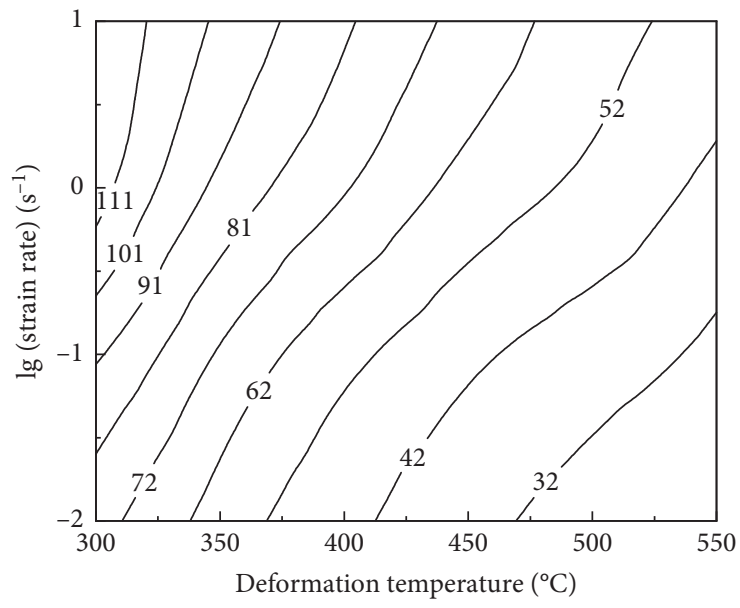

(b)

FIgURE 6: Evolution of peak flow stresses of (a) 6061 and (b) WQ1 as a function of deformation temperature and strain rate. 


$$
\dot{\varepsilon}=A[\sinh (\alpha \sigma)]^{n} \exp \left(-\frac{Q}{R T}\right) .
$$

$\dot{\varepsilon}$ is strain rate $\left(\mathrm{s}^{-1}\right), \mathrm{A} 1, \mathrm{~A} 2, \mathrm{~A}, n_{1}, \beta, n$, and $\alpha\left(\alpha=\beta / n_{1}\right)$ are constants of the material, $\sigma$ is the flow stress (MPa), $Q$ is deformation activation energy $(\mathrm{kJ} / \mathrm{mol}), R$ is the gas constant $\left(8.314 \mathrm{~J} \cdot \mathrm{mol}^{-1} \cdot \mathrm{K}^{-1}\right), T$ is the absolute temperature $(\mathrm{K})$, and $Z$ is Zener-Hollomon parameter.

Based on previous study, a power relationship equation (2) is applied to low flow stress situation. On the contrary, an exponential relationship equation (3) is applied to high flow stress situation. The hyperbolic sine law equation (4) is suitable for wide range of flow stress situation. Applying natural logarithms to both sides of equations (2)-(4), the equations for constants of the materials can be obtained:

$$
\begin{aligned}
& \ln \dot{\varepsilon}=\ln A_{1}+n_{1} \ln \sigma-\frac{Q}{R T}, \\
& \ln \dot{\varepsilon}=\ln A_{2}+\beta \sigma-\frac{Q}{R T}, \\
& \ln \dot{\varepsilon}=\ln A+n \sinh \alpha \sigma-\frac{Q}{R T} .
\end{aligned}
$$

Subsequently, the values of $n_{1}$ and $\beta$ can be determined by the slope of the plots for $\ln \dot{\varepsilon}-\ln \sigma$ and $\ln \dot{\varepsilon}-\sigma$, respectively. According to $\alpha=\beta / n_{1}$, the value of $\alpha$ can be obtained by substituting the average values of $n_{1}$ and $\beta$.

After undergoing partial differentiation on equation (7), $Q$ for hot deformation of the studied alloys can be calculated as

$$
Q=R\left\{\frac{\partial \ln \dot{\varepsilon}}{\partial \ln [\sinh (\alpha \sigma)]}\right\}_{T} \cdot\left\{\frac{\partial \ln [\sinh (\alpha \sigma)]}{\partial(1 / T)}\right\}_{\dot{\varepsilon}}=R M N
$$

By substituting experimental data of 6061 and WQ1 into equation (8), the corresponding material constants (A, $\beta, \alpha$, and $n$ ) and $Q$ can be obtained and calculated values are presented in Table 2. The average $Q$ value of 6061 alloy is $148.73 \mathrm{~kJ} / \mathrm{mol}$; meanwhile $Q$ value of WQ1 reaches $189.12 \mathrm{~kJ} / \mathrm{mol}$. Apparently, $Q$ of WQ1 is higher than that of 6061, which is caused by synthetic effect of higher solute level of $\mathrm{Mn}$ and $\alpha-\mathrm{Al}(\mathrm{MnCr}) \mathrm{Si}$ dispersoids in WQ1. Solute atoms can work as obstacles to restrict dislocation motions during hot deformation, causing ascending activation energy of alloys $[19,22] . \alpha-\mathrm{Al}(\mathrm{MnCr}) \mathrm{Si}$ dispersoids are able to effectively pin dislocation migration as well as subgrain boundaries migration. Therefore, extra energy was required for dislocations or subgrain boundaries for unpinning from $\alpha-\mathrm{Al}(\mathrm{MnCr}) \mathrm{Si}$ dispersoids, therefore resulting in a greater $Q$ for WQ1 and higher hot deformation resistance.

Recent works $[10,14,23]$ demonstrate that activation energy for hot deformation of a given material varies with deformation parameters rather than remaining a constant. Shi et al. [13] proposed a revised Sellars' constitutive equation (equation (9)) to present the relation between activation energy and deformation parameters ( $T$ and $\dot{\varepsilon}$ ) (equation (12)):
TABLE 2: Materials constants and Q of WQ1 and 6061 alloys.

\begin{tabular}{lccccc}
\hline Alloys & $A\left(\mathrm{~s}^{-1}\right)$ & $\beta$ & $\alpha\left(\mathrm{MPa}^{-1}\right)$ & $n$ & $Q(\mathrm{~kJ} / \mathrm{mol})$ \\
\hline 6061 & $8.9 \times 10^{12}$ & 0.167 & 0.023 & 4.95 & 148.73 \\
WQ1 & $2.9 \times 10^{9}$ & 0.197 & 0.018 & 7.33 & 189.12 \\
\hline
\end{tabular}

$$
\begin{aligned}
\dot{\varepsilon} & =A_{(T, \dot{\varepsilon})}[\sinh (\alpha \sigma)]^{n_{(T)}} \exp \left(-\frac{Q_{(T, \dot{\varepsilon})}}{R T}\right), \\
Q_{(T, \dot{\varepsilon})} & =R M_{(T)} N_{\dot{\varepsilon}},
\end{aligned}
$$

$M_{(T)}$ represents the slope of $\ln (\dot{\varepsilon})$ versus $\ln \left[\sinh \left(\alpha \sigma_{p}\right)\right]$ plotted at different deformation temperatures and $N_{\dot{\varepsilon}}$ is the slope of $\ln \left[\sinh \left(\alpha \sigma_{p}\right)\right]$ versus $1 / T$ plotted at different strain rates. The value of $Q$ at various deformation conditions can be obtained according to $M$ and $N$; hence, the corresponding $Q$ maps for 6061 and WQ1 can be illustrated (Figure 7).

For 6061 alloys (Figure $7(\mathrm{a})$ ), $Q$ is $170.82 \mathrm{~kJ} / \mathrm{mol}$ at $300^{\circ} \mathrm{C}$ with strain rate of $0.01 / \mathrm{s}$, while it degrades to $132.33 \mathrm{~kJ} / \mathrm{mol}$ at $550^{\circ} \mathrm{C}$ with strain rate of $10 / \mathrm{s}$. For WQ1 alloys (Figure $7(\mathrm{~b})$ ), $Q$ is about $208.12 \mathrm{~kJ} / \mathrm{mol}$ at $300^{\circ} \mathrm{C}$ with strain rate of $0.01 / \mathrm{s}$, while it decreases to $152.03 \mathrm{~kJ} / \mathrm{mol}$ at $550^{\circ} \mathrm{C}$ with strain rate of $0.01 / \mathrm{s}$. Q of WQ1 is significantly increased compared to that of 6061 under the same deformation conditions. It is reported that $Q$ is directly connected with density and movement of dislocations [10]. The presence of $\alpha-\mathrm{Al}(\mathrm{MnCr}) \mathrm{Si}$ dispersoids in WQ1 alloy effectively retards movement of dislocations and (sub)grain boundaries, resulting in higher $Q$ value than 6061's.

As shown in Figure 7, it is obvious that $Q$ is not constant but is influenced by thermomechanical conditions, that is, deformation temperatures as well as strain rates. Q of 6061 and WQ1 alloy decreases with increasing deformation temperatures and increasing strain rates. On one hand, dynamic restoration process is expedited when the alloy is deformed at higher strain rates [24], leading to promoted dislocation movement. On the other hand, increasing strain rates leads to increasing resolved shear stress along the dislocation slipping direction [25], resulting in advanced initiation of dislocation movement. With increasing deformation temperature, DRV and DRX are greatly boosted, including formation, growth, and polygonization of welldefined subgrains as well as formation of recrystallized grains, respectively. Therefore, the activation energy decreases with increasing deformation temperature.

The activation energy can reflect workability of alloys under various deformation conditions. Higher $Q$ domains in activation map are often related to inferior workability [26], while lower $Q$ domains indicate less processing difficulty. There is a correlation between $Q$ and hot deformation mechanism as well as microstructural evolution, which will be discussed in the following section.

3.4. Processing Maps. Based on the dynamic material model, the processing map is established by superposition of a flow instability map over a power dissipation efficiency map. The efficiency of power dissipation $(\eta)$ is employed to assess the 


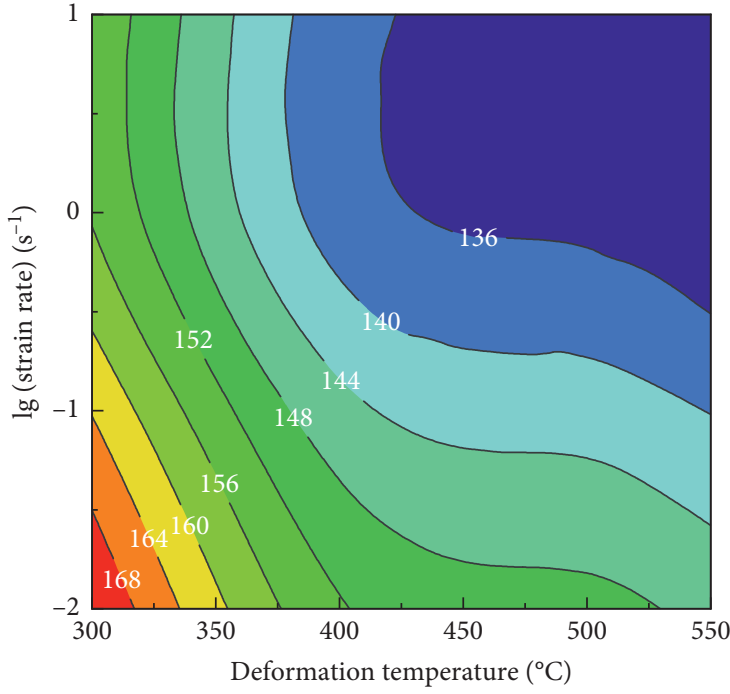

(a)

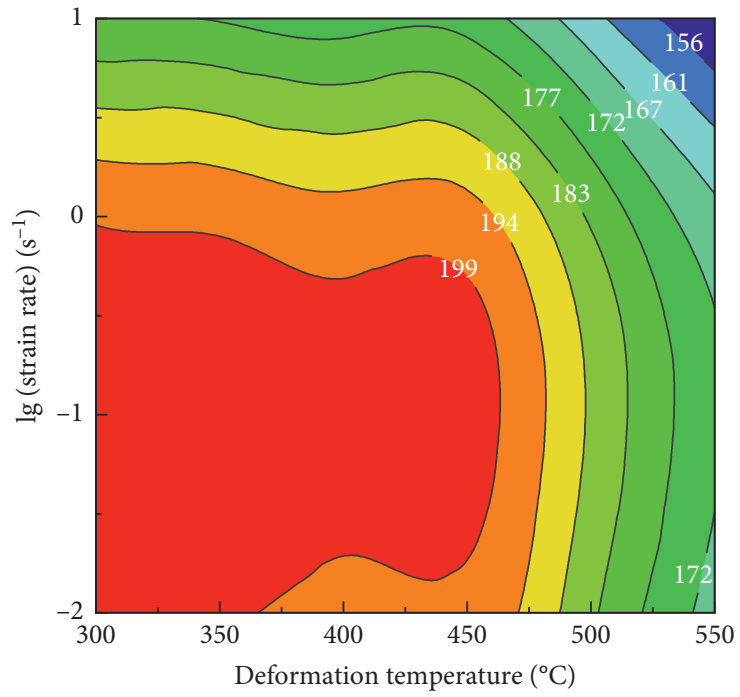

(b)

FIGURE 7: Q maps of (a) 6061 and (b) WQ1 evolution as a function of processing parameters.

power dissipation capacity of the material, which is represented as $[27,28]$

$$
\eta=\frac{2 m}{m+1}
$$

where $m$ is strain rate sensitivity.

Basically, higher efficiency of power dissipation indicates that more power is consumed by microstructural evolution, meaning better hot workability. The flow instability of the material, including microcracks, flow localization, and adiabatic shear bands, can be expressed by a parameter $(\xi)$ $[8,29,30]$ :

$$
\xi=\frac{\partial \ln (m / m+1)}{\partial \ln \dot{\varepsilon}} .
$$

The instability map is composed of two parts according to the value of $\xi$. One is the processing zone, which is considered as safe domain when $\xi>0$, while the remaining part $(\xi<0)$ is taken as flow instability domain.

Figure 8 shows the processing maps at the true strain of 1.2 for 6061 and WQ1 alloys as a function of deformation temperatures and strain rates. As shown in Figure 8, the contour numbers represent the value of power dissipation efficiency and the shadow area stands for instability regions. A safe processing domain is always with a high-power dissipation efficiency and absence from instability region. The selected safe domains are marked in red boxes in Figure 8 and the corresponding processing window values of deformation temperatures and strain rates are listed in Table 3 .

As shown in Figure 8(a) and Table 3, there are three safe domains for 6061 alloys; domain I locates at temperatures ranging from 485 to $550^{\circ} \mathrm{C}$ with strain rates of $0.01-0.08 \mathrm{~s}^{-1}$ where power dissipation efficiency is $0.34-0.40$ and domain II locates at temperatures of $440-480^{\circ} \mathrm{C}$ and strain rates of $0.05-0.6 \mathrm{~s}^{-1}$ with power dissipation efficiency of 0.34 , while optimal domain III covers the region with higher temperatures and higher strain rates $\left(530-550^{\circ} \mathrm{C}, 6-10 \mathrm{~s}^{-1}\right)$. For WQ1 alloys (Figure $8(\mathrm{~b})$ ), there is mainly one safe domain, which locates at temperature ranging from 485 to $550^{\circ} \mathrm{C}$ with strain rates of $0.01-0.1 \mathrm{~s}^{-1}$ whose power dissipation efficiency is $0.26-0.29$. Comparing processing maps of 6061 and WQ1 alloys, the safe domain of both alloys locates at high deformation temperatures with low strain rates but 6061 alloy is accompanied with higher power dissipation efficiency. It has been reported $[31,32]$ that the deformation mechanism is DRV if power dissipation efficiency value during hot deformation is less than 0.3 ; otherwise, higher value is associated with DRX, which indicates that the dynamic softening mechanism of WQ1 is inhibited by $\alpha-\mathrm{Al}(\mathrm{MnCr}) \mathrm{Si}$ dispersoids. This point will be verified in the examination of microstructure evolution part. Overall, safe processing domain and low activation energy should be key determinants for the optimum workability and elimination of deformation defects.

\subsection{Microstructure Evolution}

3.5.1. Interpretation of Safe Domains. Figures 9(a) and 9(b) show the microstructures of deformed 6061 and WQ1 alloys at safe domains with low $Q\left(550^{\circ} \mathrm{C}\right.$ and $\left.10 \mathrm{~s}^{-1}\right)$. The microstructures of both alloys mainly consisted of elongated grains and a certain area fraction of recrystallized grains, indicating a typical DRV process. Moreover, different degrees of recrystallization occur for 6061 and WQ1 alloys. It can be seen from Figure 9(a) that recrystallization happens extensively along deformed grain boundaries (marked by black box) and the area fraction of recrystallized grains is as much as $50.12 \%$ for 6061 alloy. Figure 9(b) shows that partial recrystallization mainly initiates around triple junction grain boundaries (noted by black box) and the area fraction of recrystallized grains is only $9.78 \%$ for WQ1 alloy. Particlestimulated nucleation (PSN) of recrystallization has been 


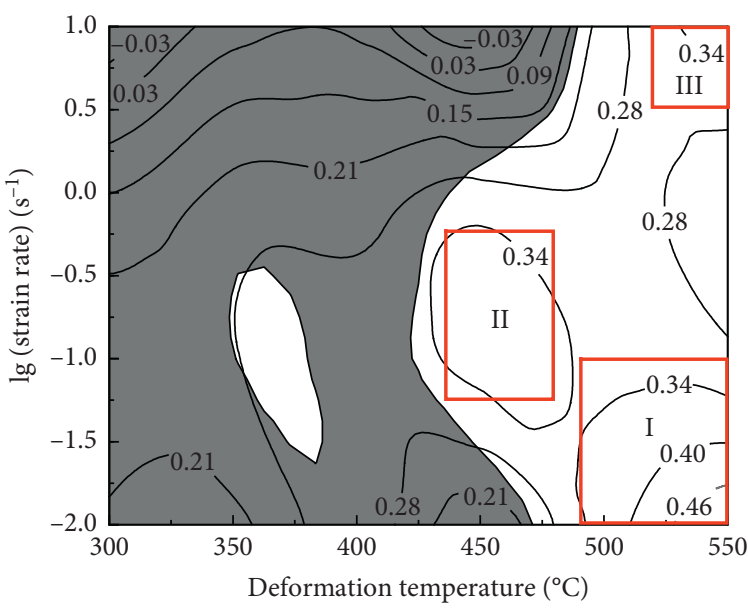

(a)

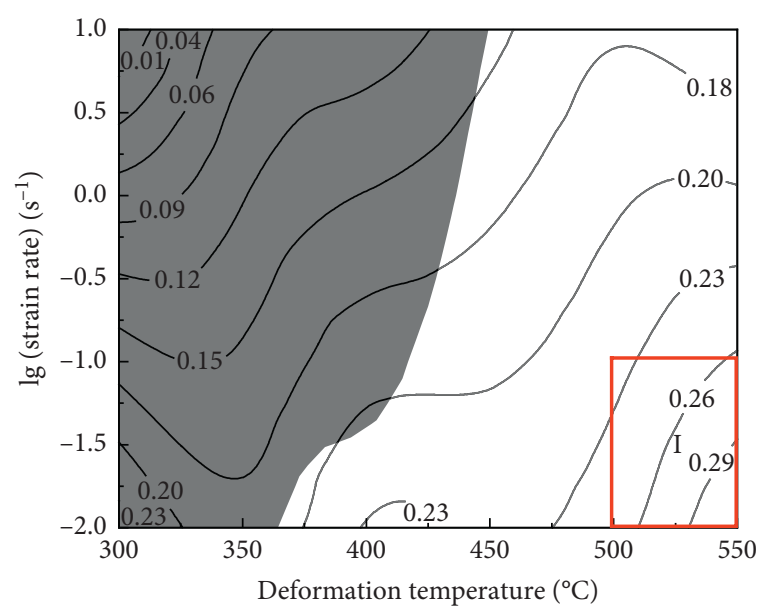

(b)

FIgure 8: Processing maps of 6061 (a) and WQ1 (b) developed at the true strain of 1.2.

TABLE 3: Safe processing domains of 6061 and WQ1.

\begin{tabular}{lcr}
\hline Alloys & Low strain rate domains (I \& II) & High strain rate domains (III) \\
\hline \multirow{2}{*}{6061} & $485-550^{\circ} \mathrm{C}, 0.01-0.08 \mathrm{~s}^{-1}$ & $530-550^{\circ} \mathrm{C}, 6-10 \mathrm{~s}^{-1}$ \\
WQ1 & $440-480^{\circ} \mathrm{C}, 0.05-0.6 \mathrm{~s}^{-1}$ & \\
\hline
\end{tabular}

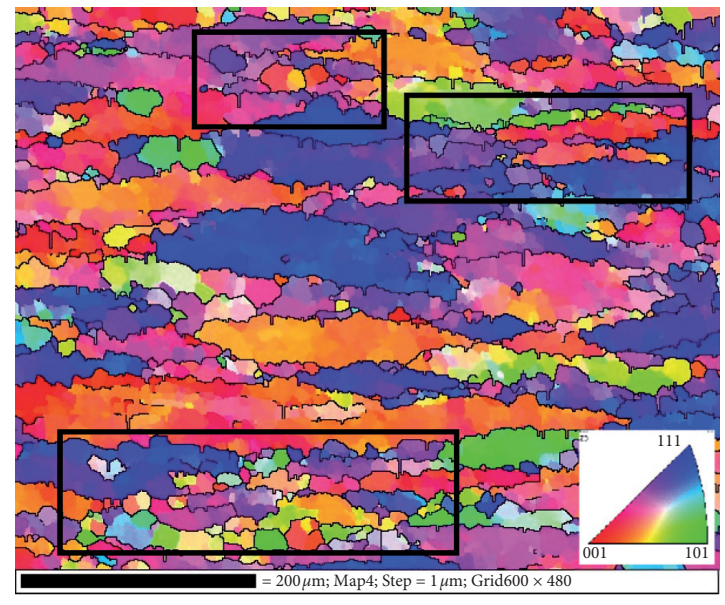

(a)

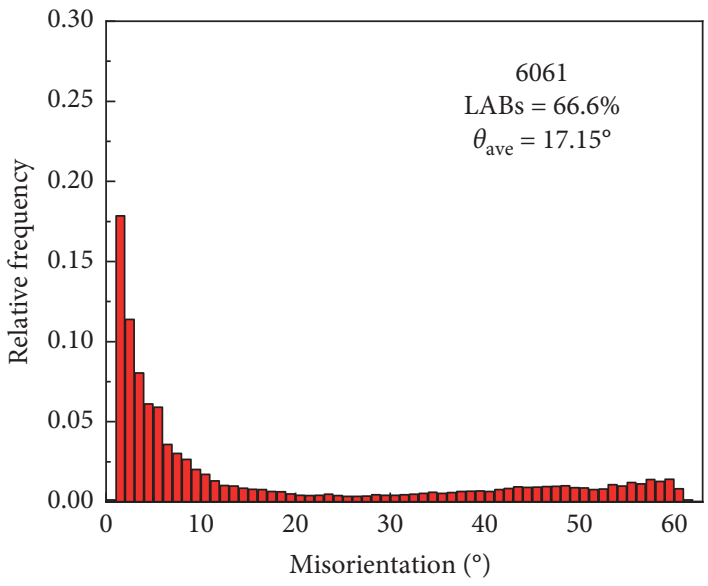

(c)

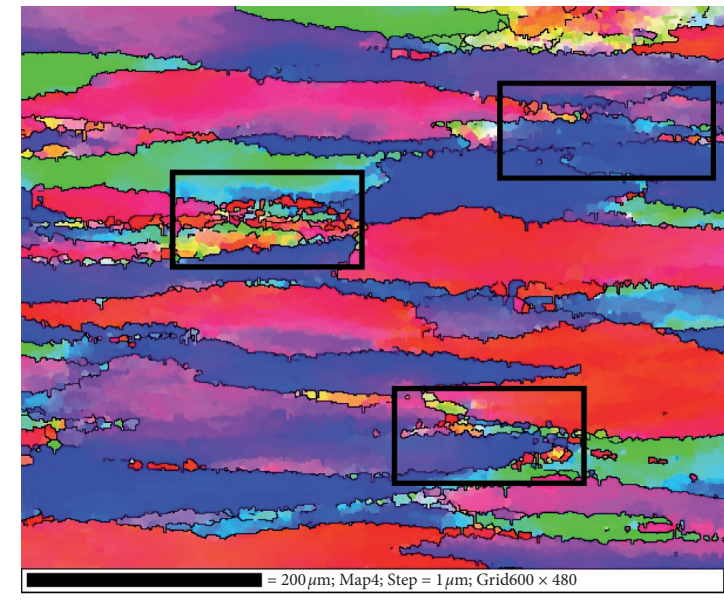

(b)

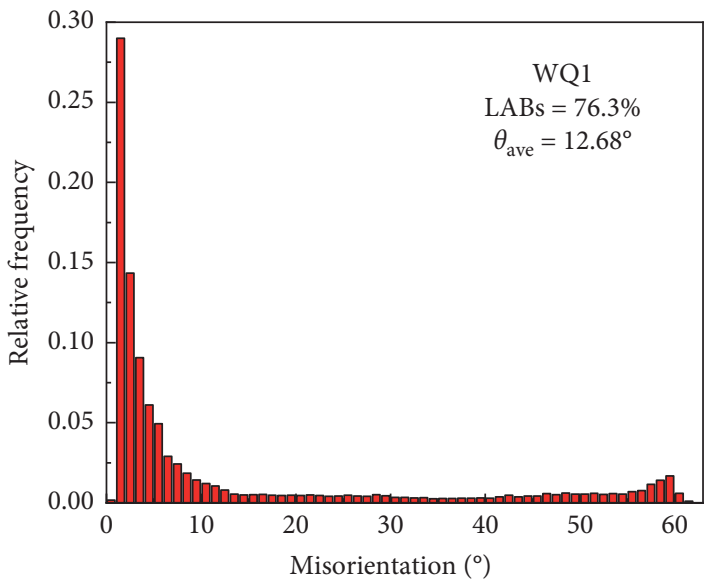

(d)

Figure 9: Continued. 


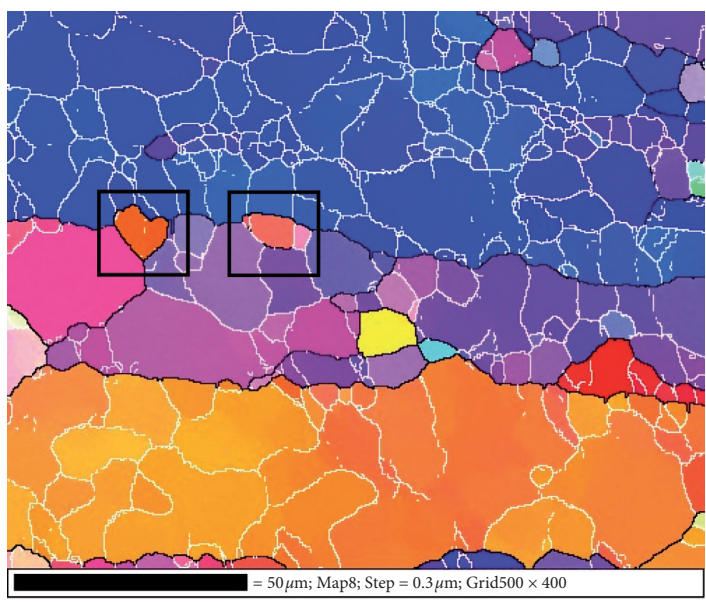

(e)

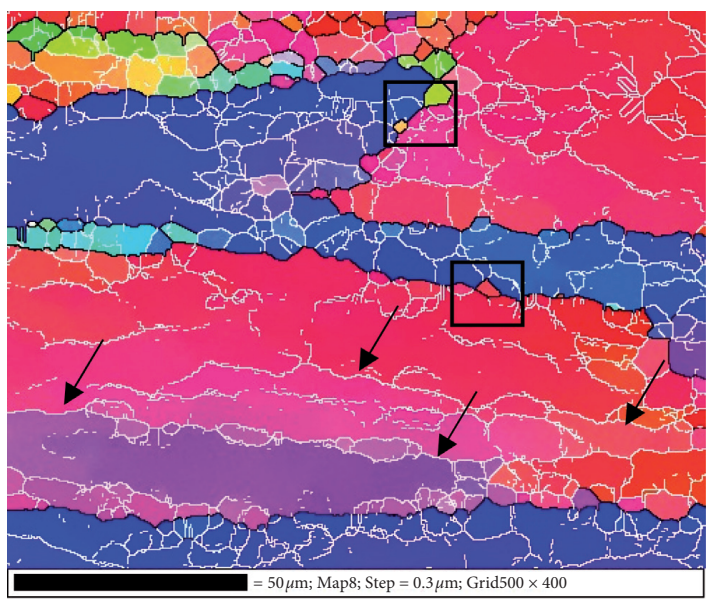

(f)

Figure 9: EBSD maps (a, b), misorientation angle distribution (c, d), and substructures (e, f) of 6061 (a, c, e) and WQ1 (b, d, f) alloys compressed at $550^{\circ} \mathrm{C}$ and $10 \mathrm{~s}^{-1}$ to strain of 1.2 . The inset in (a) is inversed pole figure coloring.

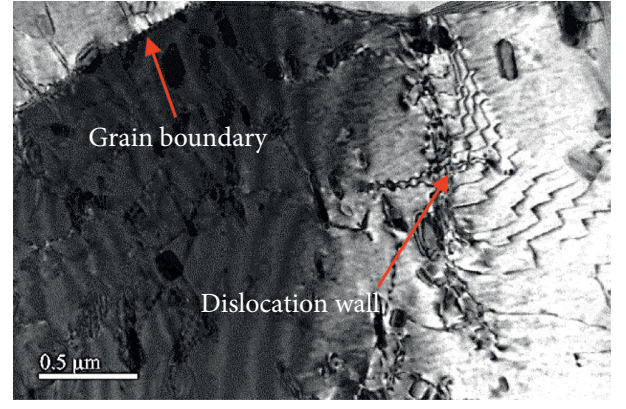

(a)

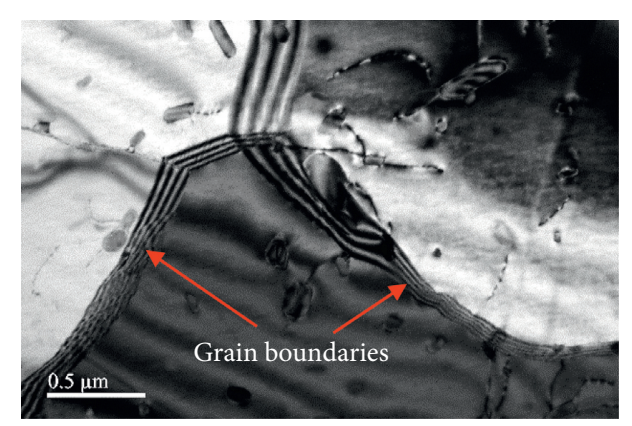

(b)

Figure 10: Interaction of dispersoids with (a) dislocations/dislocation walls at $450^{\circ} \mathrm{C}$ and $0.1 \mathrm{~s}^{-1}$ and (b) subgrain boundaries at $550^{\circ} \mathrm{C}$ and $0.1 \mathrm{~s}^{-1}$.

identified as an active nucleation mechanism of DRX for hot deformed alloys, which is strongly dependent on the size of second phase particles. Normally, particles can induce PSN effect and enhance the DRX when they are larger than $1 \mu \mathrm{m}$, while they can, on the other hand, suppress the DRX for the strong pining effect when particles are smaller than $1 \mu \mathrm{m}$ $[33,34]$. Hence, recrystallization in WQ1 alloy is severely restrained by the presence of large amount of nanoscale $(\sim 120 \mathrm{~nm}) \alpha-\mathrm{Al}(\mathrm{MnCr}) \mathrm{Si}$ dispersoids. Misorientation distributions based on Figures 9(a) and 9(b) are presented in Figures 9(c) and 9(d), respectively. It is obvious that WQ1 alloys hold more percentage of LABs and lower average misorientation angle $\left(\theta_{\text {ave }}\right)$ compared to 6061 alloys, which is consistent with results of Figures 9(a) and 9(b). The substructure of 6061 (Figure 9(e)) is composed of abundant equiaxed subgrains with LABs and recrystallized grains with size of $10 \mu \mathrm{m}$. It can be concluded that the main mechanism for DRX is continuous dynamic recrystallization [35]. The recrystallized grains formed by transformation of LABs to HABs (pointed out by black box). For WQ1 alloys (Figure 9(f)), the microstructure is composed of subgrains and recrystallized grains with size around $5 \mu \mathrm{m}$. It should be noticed that some subgrains in WQ1 alloys are elongated rather than equiaxed (marked by black arrows), indicating that subgrain rotation is strongly suppressed. Owing to pinning effect of $\alpha$ - $\mathrm{Al}(\mathrm{MnCr}) \mathrm{Si}$ dispersoids, subgrain rotation and (sub)grain boundaries migration are inhibited. Hence, DRV was main dynamic softening mechanism for WQ1 alloy at its safe processing domain. Figure 10(a) demonstrated the interaction of $\alpha-\mathrm{Al}(\mathrm{MnCr}) \mathrm{Si}$ dispersoids with dislocation and dislocation walls when WQ1 was deformed at $450^{\circ} \mathrm{C}$ and $0.1 \mathrm{~s}^{-1}$. It can be seen that dislocation walls movement is retarded and dislocations bow when encountered with dispersoids, showing a strong pinning effect of $\alpha-\mathrm{Al}(\mathrm{MnCr}) \mathrm{Si}$ dispersoids on dislocation migration. Moreover, dispersoids also inhibit grain boundaries (Figure 10(b)), even though WQ1 was compressed at $550^{\circ} \mathrm{C}$. Hence, DRV in WQ1 is significantly restrained due to pinning effects of $\alpha-\mathrm{Al}(\mathrm{MnCr}) \mathrm{Si}$ dispersoids on dislocation motions and grain rotations [19, 24].

3.5.2. Interpretation of Instable Domains. The flow instability is often related to generation of microstructural 


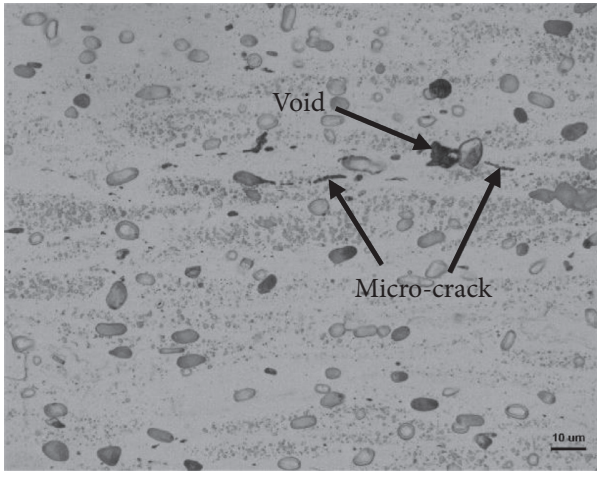

(a)

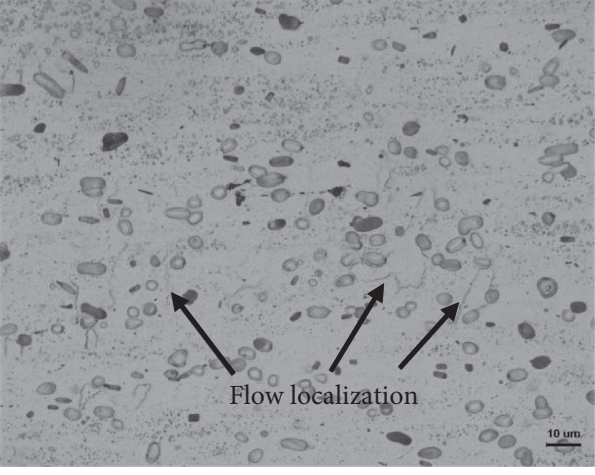

(b)

Figure 11: Optical microstructures of 6061 deformed at $300^{\circ} \mathrm{C}$ with $0.1 \mathrm{~s}^{-1}$ to strain of 1.2: (a) void and micro crack; (b) flow localization.

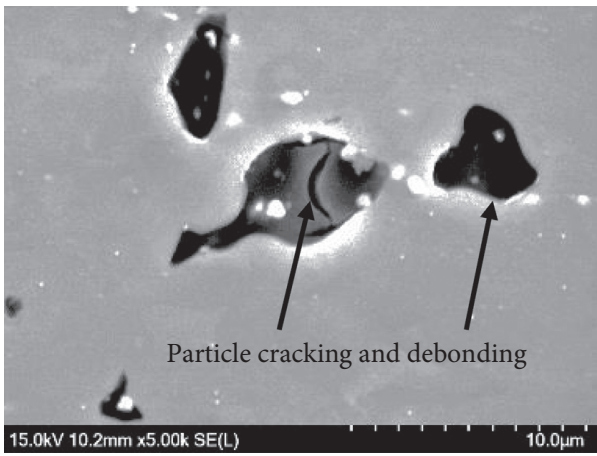

(a)

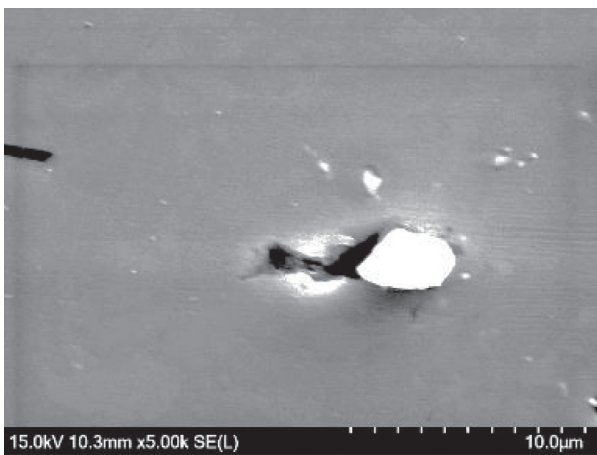

(b)

FIGURE 12: SEM micrographs of 6061 compressed at $300^{\circ} \mathrm{C}$ with $0.1 \mathrm{~s}^{-1}$ to strain of 1: (a) particle cracking and debonding; (b) micro crack.

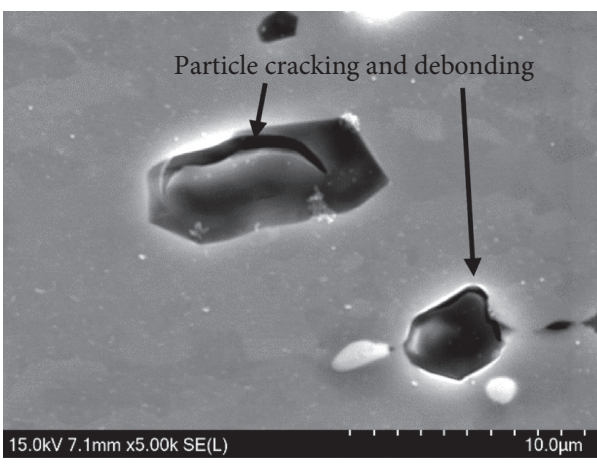

(a)

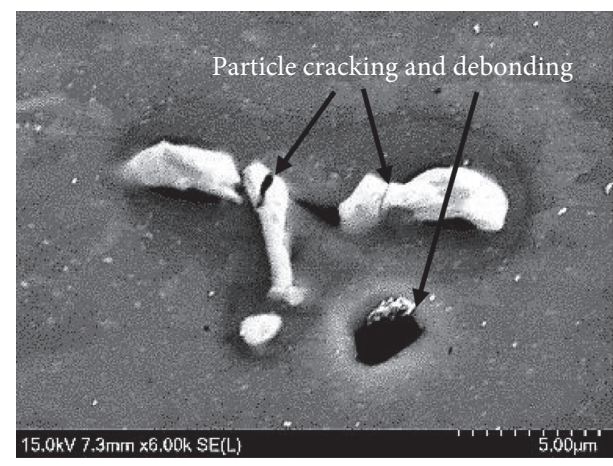

(b)

FIGURE 13: SEM micrographs of WQ1 compressed at $300^{\circ} \mathrm{C}$ with $0.1 \mathrm{~s}^{-1}$ to strain of 1: (a) particle cracking and debonding; (b) micro cracks.

defects, including flow localization, adiabatic shear bands, micro/macro cracks, and intermetallic/particle cracking and debonding. Micro/macro damages are closely related to shear bands and flow localization. Based on research of Ramanathan et al. [36], flow localization refers to discontinuous and inhomogeneous deformation around adjacent areas resulting from composition differences, interphase boundaries, and loading conditions [37].
The optical micrographs of 6061 deformed at $300^{\circ} \mathrm{C}$ with $0.1 \mathrm{~s}^{-1}$ to a strain of 1.2 were shown in Figure 11. Micro cracks and voids (marked by arrows) are observed around intermetallic particles indicating the formation of micro defects related to intermetallic particles.

In flow instable domain of 6061 alloys, cracking of primary $\mathrm{Mg}_{2} \mathrm{Si}$ phases (pointed in Figure 12(a)) along compression direction and interfacial debonding between 
$\mathrm{Mg}_{2} \mathrm{Si}$ and $\mathrm{Al}$ matrix was observed. Those sites are preferential places for micro crack formation and propagation. Flow localization happens around brittle Fe-bearing particles (Figure 12(b)) and cracked Fe bearing intermetallic causes matrix cracks initiation and propagate perpendicular to compression direction.

As the compression proceeds, both primary $\mathrm{Mg}_{2} \mathrm{Si}$ and $\mathrm{Fe}$-containing particles are prone to cracking and debonding rather than deforming in WQ1 alloys (Figure 13). Thus inhomogeneous deformation leads to severe stress concentration and enables cracking at the interface between the second phase particles and $\mathrm{Al}$ matrix under the action of external loading. Visible voids and cracks formed due to flow localization (Figures 13(a) and 13(b)) and then the pores grew and finally formed a fracture. Multiple voids and micro cracks tend to expand by linking adjacent voids.

\section{Conclusions}

(1) A great amount of $\alpha$ dispersoids formed in WQ1 alloy, which is with addition of $\mathrm{Mn}$ and $\mathrm{Cr}$, while limited $\alpha$ dispersoids were observed in 6061 alloy. Flow stresses of both alloys increased with decreasing temperatures and increasing strain rates. Furthermore, flow stresses of WQ1 alloy were higher than those of 6061 alloy under all deformation conditions owing to dispersion strengthening caused by $\alpha$ - $\mathrm{Al}(\mathrm{MnCr}) \mathrm{Si}$ dispersoids.

(2) The materials constants in constitutive equation and activation energies of WQ1 and 6061 alloys during hot deformation were calculated by applying constitutive analysis. Due to presence of $\alpha-\mathrm{Al}(\mathrm{MnCr}) \mathrm{Si}$ dispersoids in WQ1, activation energy of it for hot deformation was $40.4 \mathrm{~kJ} / \mathrm{mol}$ higher than that of 6061.

(3) The activation energy maps and processing maps of the two alloys during hot deformation were constructed. The activation energy of both alloys is variant and is greatly influenced by deformation temperatures and strain rates. Optimized hot deformation parameters for WQ1 and 6061 were determined with high dissipation efficiency and low activation energy within safe processing domains.

(4) The microstructure analysis revealed that main dynamic softening mechanism for 6061 under optimized hot deformation parameters was DRV and extensive DRX, while DRV was predominant softening mechanism for WQ1 due to strong pinning effect of $\alpha-\mathrm{Al}(\mathrm{MnCr}) \mathrm{Si}$ dispersoids on subgrain rotation and subgrain boundaries migration.

(5) For both alloys, flow instability was associated with cracking and debonding of intermetallic particles as well as void formation during hot deformation.

\section{Data Availability}

All experimental data are available.

\section{Disclosure}

Part of the manuscript was presented in Sub-Session: Materials Forming and Modeling, but the manuscript was not submitted in the session. Furthermore, the content of the manuscript was revised.

\section{Conflicts of Interest}

The authors declare no conflicts of interest.

\section{Acknowledgments}

The authors acknowledge the financial support provided by Jincheng Science and Technology Plan Projects of Shanxi Province (no. 201702014) and National Natural Science Foundation of China (Grant no. U1864209).

\section{References}

[1] L. Ding, Z. Jia, J. F. Nie et al., "The structural and compositional evolution of precipitates in Al-Mg-Si-Cu alloy," Acta Materialia, vol. 145, pp. 437-450, 2018.

[2] C. L. Liu, Q. Du, N. C. Parson, and W. J. Poole, “The interaction between $\mathrm{Mn}$ and $\mathrm{Fe}$ on the precipitation of $\mathrm{Mn} / \mathrm{Fe}$ dispersoids in Al-Mg-Si-Mn-Fe alloys," Scripta Materialia, vol. 152, pp. 59-63, 2018.

[3] X. Qian, N. Parson, and X. G. Chen, "Effects of Mn addition and related Mn-containing dispersoids on the hot deformation behavior of 6082 aluminum alloys," Materials Science and Engineering: A, vol. 764, Article ID 138253, 2019.

[4] Q. Du, W. J. Poole, M. A. Wells, and N. C. Parson, "Microstructure evolution during homogenization of Al-Mn-Fe-Si alloys: modeling and experimental results," Acta Materialia, vol. 61, no. 13, pp. 4961-4973, 2013.

[5] L. Lodgaard and N. Ryum, "Precipitation of dispersoids containing $\mathrm{Mn}$ and/or $\mathrm{Cr}$ in $\mathrm{Al}-\mathrm{Mg}-\mathrm{Si}$ alloys," Materials Science and Engineering A, vol. 283, no. 1-2, pp. 144-152, 2000.

[6] J. Liu, Z. Cui, and C. Li, "Analysis of metal workability by integration of FEM and 3-D processing maps," Journal of Materials Processing Technology, vol. 205, no. 1-3, pp. 497505, 2008.

[7] J. Qin, Z. Zhang, and X. G. Chen, "Hot deformation and processing maps of $\mathrm{Al}-15 \% \mathrm{~B}_{4} \mathrm{C}$ composites containing $\mathrm{Sc}$ and Zr," Journal of Materials Engineering and Performance, vol. 26, no. 4, pp. 1673-1684, 2017.

[8] Y. V. R. K. Prasad and T. Seshacharyulu, "Processing maps for hot working of titanium alloys," Materials Science and Engineering: A, vol. 243, no. 1-2, pp. 82-88, 1998.

[9] H. Z. Li, H. J. Wang, X. P. Liang, H. T. Liu, Y. Liu, and X. M. Zhang, "Hot deformation and processing map of 2519A aluminum alloy," Materials Science and Engineering: A, vol. 528, no. 3, pp. 1548-1552, 2011.

[10] S. Wang, L. G. Hou, J. R. Luo, J. S. Zhang, and L. Z. Zhuang, "Characterization of hot workability in AA 7050 aluminum alloy using activation energy and 3-D processing map," Journal of Materials Processing Technology, vol. 225, pp. 110-121, 2015.

[11] X. Kai, C. Chen, X. Sun, C. Wang, and Y. Zhao, "Hot deformation behavior and optimization of processing parameters of a typical high-strength $\mathrm{Al}-\mathrm{Mg}-\mathrm{Si}$ alloy," Materials \& Design, vol. 90, pp. 1151-1158, 2016. 
[12] J. J. Jonas, C. M. Sellars, and W. J. M. C. G. Tegart, "Strength and structure under hot-working conditions," International Materials Reviews, vol. 14, no. 1, pp. 1-24, 1969.

[13] C. Shi, W. Mao, and X. G. Chen, "Evolution of activation energy during hot deformation of AA7150 aluminum alloy," Materials Science and Engineering: A, vol. 571, pp. 83-91, 2013.

[14] J. Qin, Z. Zhang, and X. G. Chen, "Evolution of activation energy during hot deformation of $\mathrm{Al}-15 \% \mathrm{~B}_{4} \mathrm{C}$ composites containing Sc and Zr," AIMS Materials Science, vol. 6, no. 4, pp. 484-497, 2019.

[15] J. Hu, J. Teng, X. Ji, D. Fu, W. Zhang, and H. Zhang, "Enhanced mechanical properties of an $\mathrm{Al}-\mathrm{Mg}$-Si alloy by repetitive continuous extrusion forming process and subsequent aging treatment," Materials Science and Engineering: A, vol. 695, pp. 35-44, 2017.

[16] M. Nakai and G. Itoh, "The effect of microstructure on mechanical properties of forged 6061 aluminum alloy," Materials Transactions, vol. 55, no. 1, pp. 114-119, 2014.

[17] H. E. Hu, L. Zhen, L. Yang, W. Z. Shao, and B. Y. Zhang, "Deformation behavior and microstructure evolution of 7050 aluminum alloy during high temperature deformation," Materials Science and Engineering: A, vol. 488, no. 1-2, pp. 64-71, 2008.

[18] Y. J. Li and L. Arnberg, "Quantitative study on the precipitation behavior of dispersoids in DC-cast AA3003 alloy during heating and homogenization," Acta Materialia, vol. 51, no. 12, pp. 3415-3428, 2003.

[19] H. J. MacQueen, E. Evangelista, S. Spigarelli, and M. E. Kassner, Hot Deformation and Processing of Aluminum Alloys, CRC Press, Boca Raton, FL, USA, 2011.

[20] G. W. Zhang, H. Nagaumi, Y. Han, Y. Xu, C. M. Parish, and T. G. Zhai, "Effect of $\mathrm{Mn}$ and $\mathrm{Cr}$ additions on the recrystallizaiton behavior of Al-Mg-Si-Cu alloys," Materials Science Forum, vol. 877, pp. 172-179, 2016.

[21] C. Sellars and W. M. G. Tegart, "Relation between flow stress and structure in hot deformation," Memoires et Etudes Scientifiques de La Revue de Metallurgie, vol. 67, pp. 731-746, 1966.

[22] X. Huang, H. Zhang, Y. Han, W. Wu, and J. Chen, "Hot deformation behavior of 2026 aluminum alloy during compression at elevated temperature," Materials Science and Engineering: A, vol. 527, no. 3, pp. 485-490, 2010.

[23] X. Peng, W. Su, D. Xiao, and G. Xu, "Investigation on hot workability of homogenized $\mathrm{Al}-\mathrm{Zn}-\mathrm{Mg}-\mathrm{Cu}$ alloy based on activation energy and processing map," Jom, vol. 70, no. 6, pp. 993-999, 2018.

[24] F. J. Humphreys and M. Hatherly, "Recrystallization and related annealing phenomena (second edition)," in Recrystallization and Related Annealing Phenomena, F. J. Humphreys and M. Hatherly, Eds., Elsevier, Amsterdam, Netherlands, 2nd edition, 2004.

[25] C. Daniel, Thermally Activated Mechanisms in Crystal Plasticity: Pergamon Materials Series, Vol. 8, Elsevier, Amsterdam, Netherlands, 2003.

[26] Z. Mingjie, L. Fuguo, W. Shuyun, and L. Chenyi, "Characterization of hot deformation behavior of a $\mathrm{P} / \mathrm{M}$ nickel-base superalloy using processing map and activation energy," Materials Science and Engineering: A, vol. 527, no. 24-25, pp. 6771-6779, 2010.

[27] Y. V. R. K. Prasad, "Processing maps: a status report," Journal of Materials Engineering and Performance, vol. 12, no. 6, pp. 638-645, 2003.
[28] Y. V. R. K. Prasad and T. Seshacharyulu, "Modelling of hot deformation for microstructural control," International Materials Reviews, vol. 43, no. 6, pp. 243-258, 2013.

[29] Y. V. R. K. Prasad and K. P. Rao, "Processing maps for hot deformation of rolled AZ31 magnesium alloy plate: anisotropy of hot workability," Materials Science and Engineering: $A$, vol. 487, no. 1-2, pp. 316-327, 2008.

[30] Y. Sun, Z. Cao, Z. Wan et al., "3D processing map and hot deformation behavior of 6A02 aluminum alloy," Journal of Alloys and Compounds, vol. 742, pp. 356-368, 2018.

[31] W. Liu, H. Zhao, D. Li, Z. Zhang, G. Huang, and Q. Liu, "Hot deformation behavior of AA7085 aluminum alloy during isothermal compression at elevated temperature," Materials Science and Engineering: A, vol. 596, pp. 176-182, 2014.

[32] J. Yan, Q. L. Pan, B. Li, Z. Q. Huang, Z. M. Liu, and Z. M. Yin, "Research on the hot deformation behavior of Al-6.2Zn-0.70Mg-0.3Mn-0.17Zr alloy using processing map," Journal of Alloys and Compounds, vol. 632, pp. 549557, 2015.

[33] L. P. Troeger and E. A. Starke Jr., "Particle-stimulated nucleation of recrystallization for grain-size control and superplasticity in an Al-Mg-Si-Cu alloy," Materials Science and Engineering: A, vol. 293, no. 1-2, pp. 19-29, 2000.

[34] K. F. Adam, Z. Long, and D. P. Field, "Analysis of particleStimulated nucleation (PSN) dominated recrystallization for hot-rolled 7050 aluminum alloy," Metallurgical and Materials Transactions A, vol. 48, no. 4, pp. 2062-2076, 2017.

[35] T. Sakai, A. Belyakov, R. Kaibyshev, H. Miura, and J. J. Jonas, "Dynamic and post-dynamic recrystallization under hot, cold and severe plastic deformation conditions," Progress in $\mathrm{Ma}$ terials Science, vol. 60, pp. 130-207, 2014.

[36] S. Ramanathan, R. Karthikeyan, and M. Gupta, "Development of processing maps for $\mathrm{Al} / \mathrm{SiC}_{\mathrm{p}}$ composite using fuzzy logic," Journal of Materials Processing Technology, vol. 183, no. 1, pp. 104-110, 2007.

[37] R. Guemini, A. Boubertakh, and G. W. Lorimer, "Study of the recrystallization process of AlMgSi alloys containing transition elements," Journal of Alloys and Compounds, vol. 486, no. 1-2, pp. 451-457, 2009. 